\title{
REDESIGN AND MANUFACTURING BY USING DMADV METHOD
}

\author{
Devendra G. Pendokhare ${ }^{1}$, Taqui Quazi ${ }^{2}$, Prasad S. Kulkarni ${ }^{3}$ \\ ${ }^{1}$ PG Student, Mechanical Engineering Department, SCOE, Kharghar, Mumbai University, Maharashtra, India \\ ${ }^{2} \mathrm{HOD}$, Automobile Engineering Department, Saraswati college of engineering, kharghar, New Mumbai, \\ Maharashtra, India \\ ${ }^{3}$ Lecturer, Mechanical Engineering Department, Government Polytechnic, Vikramgad, MSBTE, Maharashtra, India
}

\begin{abstract}
The cost of poor Quality would help in analyzing the operating costs for effective and profitable business management. . In the era of cut throat competition, especially in automobile sector, success of an organisation resides in its ability to respond quickly to the needs of its customers. These customer needs must be attended with minimum manufacturing costs, minimum lead time to launch the product in market and delivering better performance than the existing competitors in the market.success achieved by market leaders is credited to their improvement initiatives. The customer needs must be attended with minimum manufacturing costs, and delivering better performance than the existing competitors in the market. Therefore, Indian companies in order to compete with global companies, it is very much essential to be at par, in all spheres of business aspects. Cost and Quality are two very important aspects to be globally competitive, to capture market share, to retain customers to be in business and to achieve business excellence. In the present times Six Sigma Methodology and QC Story are very famous and powerful tools and are widely used in the global industries. The increase in demand of the growing customer looking for a better quality of product has compelled corporations to adopt Six Sigma in order to improve the quality for enhanced competitive advantage. Therefore, it is very much essential to understand relation between six sigma and cost of quality and its application in automobile industry.
\end{abstract}

Keywords: Six Sigma, DMADV, DMAIC, Quality improvement

\section{INTRODUCTION}

Six sigma defines as a statistical concept that measures process in terms of defects. He goes further to argue that when used in business, it indicates defects in the outputs of a process and helps one to understand how far the processes deviate from perfection. it as a business strategy that seeks to identify and eliminate causes of errors or defects or failures in business processes by focusing on outputs that are critical to customers. On the other hand defines it as a data driven structured problem solving methodology for solving chronic issues facing a business, and a breakthrough business management process that is used to improve a company's performance by variation reduction.

Indian Automobile Industry has already started using Six Sigma Methodology for vehicle design and process improvement to survive in the global competition. It is very important to study and investigate how Six Sigma Methodology is employed in Indian Automobile Industry for designing the product or for Process Improvement and importance of Six Sigma Methodology to reduce Cost of Quality. This motivates to take up research on this topic. In the era of cut throat competition, success achieved by market leaders is credited to their improvement initiatives. A common element within many of these successful companies is the use of powerful cost of poor quality concepts in connecting improvement priorities to strategic objectives, assessing the financial impact of poor quality, understanding the root causes of poor quality, selecting high payback improvement projects and managing the Improvement initiative to simultaneously deliver improved financial performance and greater customer satisfaction.
The customer needs must be attended with minimum manufacturing costs, minimum lead time to launch the product in market and delivering better performance than the existing competitors in the market. Therefore Indian companies in order to compete with global companies, it is very much essential to be at par, in all spheres of business aspects. Cost and Quality are two very important aspects to be globally competitive, to capture market share, to retain customers to be in business and to achieve business excellence. Six Sigma is the powerful methodology to drive improvement initiatives and reduce cost of quality.

Organizations choose to implement Six Sigma for numerous reasons. Reasons for implementing Six Sigma can vary from one organization to another, however, the list below present the most common reasons for organizations to implement Six Sigma to resolve issues facing the organization:

- Cost reduction

- Cycle time reduction

- Error and waste reduction

- Increase competitive advantage

- Improve customer satisfaction

- Increase shareholder value

- Change company culture

\section{OBJECTIVES}

$>\quad$ To study Six Sigma methodology extensively for both improvement of existing process and design for Six Sigma.

$>$ To Study how Six Sigma methodology helps in reduction of cost of poor quality. 
> To understand how Six Sigma methodology supports Knowledge Management.

$>\quad$ To understand the synergic effect of the combination of two powerful methods Lean and Six Sigma and its positive impact in increasing speed and effectiveness of any process within the organization.

$>$ To study various applications and benefits of implementing Six Sigma.

\section{METHODOLOGY}

Six Sigma is a management strategy that maximizes customer satisfaction and minimizes the defects that create customer dissatisfaction. Six sigma methodologies can be used for improvement of process (called DMAIC) and also is a powerful tool for new product design or improvement in the existing product design (called DMADV). The five step DMAIC approach of Six Sigma reduces the defects in process, product or service. Flow charts, Pareto analysis, Cause \& Effect diagrams are the most frequently used basic analysis and measurement tools by Six Sigma implementation teams. Investigation as regards application of Six Sigma methodology for process improvement in Indian automobile industry is done and complete framework is prepared and illustrated.

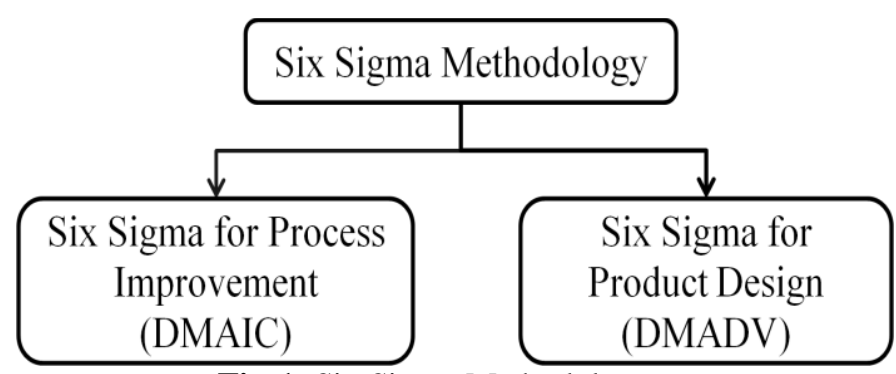

Fig-1: Six Sigma Methodology

$>\quad$ The Six Sigma DMAIC (Define, Measure, Analyze, Improve, and Control) is an improvement system for existing processes for incremental improvement.

$>$ The Six Sigma DMADV (Define, Measure, Analyze, Design, and Verify) is an improvement system used to develop new processes or products. $>\quad$ Define the project goals and customer (internal and external) deliverables

$>$ Measure and determine customer needs and specifications

$>$ Analyze the process options to meet the customer needs

$>$ Design (detailed) the process to meet the customer needs

$>\quad$ Verify the design performance and ability to meet customer needs

\subsection{Define Problem or Opportunity}

Problem is identified from voice of customer or from voice of process. Voice of customer could be customer complaint for performance / defect, field failure, critical customer issues, etc. Voice of business could be internal defects, rework, internal rejections, internal quality issues, other business issues etc. Define the goals of the new process. Identify exactly what is being designed or changed. Why is the change being made? Using the Quality Function Deployment (QFD) or Analytic Hierarchical Process tools to insure that the goals are compatible with consumer demand and the company's overall strategy.

Organizations may use right from 7 QC tools, Quality Circles, Kizens, Small Group Activities to the modest tools like Six Sigma Methodology or QC Story Approach for problem solving depending upon the nature and complexity of the problem. Where problem is chronic in nature and problem is known, however, reasons are not known, everything seems to be right, however, defects are getting generated, and such complex problems are solved using Six Sigma Methodology.

\section{DMADV}

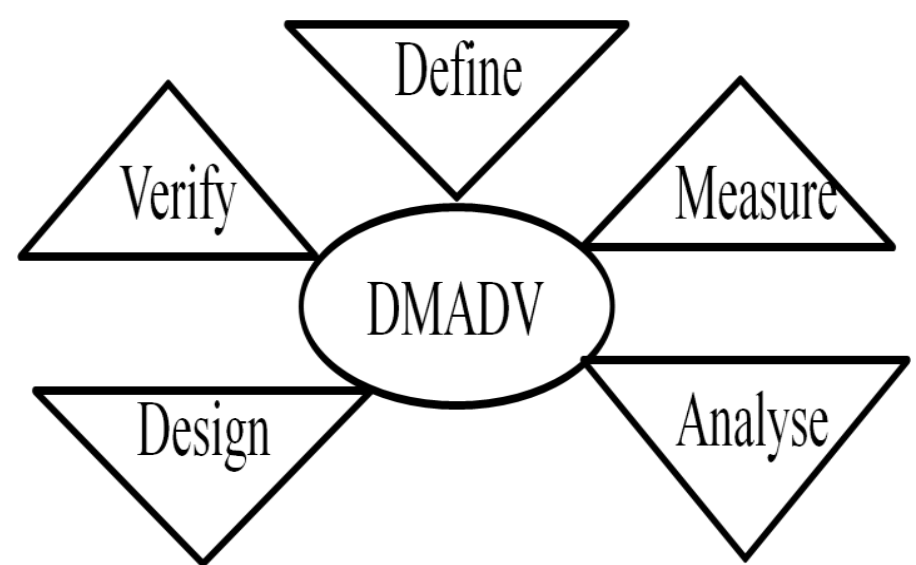

Fig-2: Road map for DMADV 
Table-1: six sigma methodology for product design (DMADV)

\begin{tabular}{|c|c|c|c|c|}
\hline Define Opportunity & $\begin{array}{l}\text { Measure } \\
\text { Performance }\end{array}$ & Analyze Opportunity & Design New Product & Verify Product Design \\
\hline 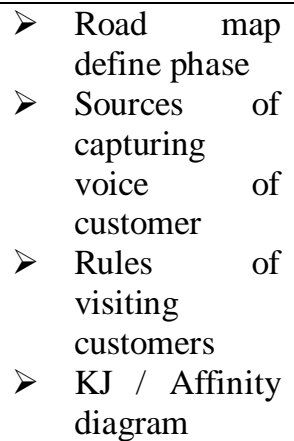 & $\begin{array}{l}>\begin{array}{l}\text { Road map } \\
\text { measure } \\
\text { phase }\end{array} \\
\text { Quality } \\
\text { function } \\
\text { deployment } \\
\text { (QFD) } \\
>\text { Advantages } \\
\text { of QFD }\end{array}$ & 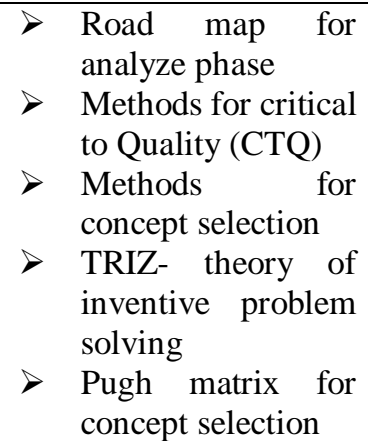 & 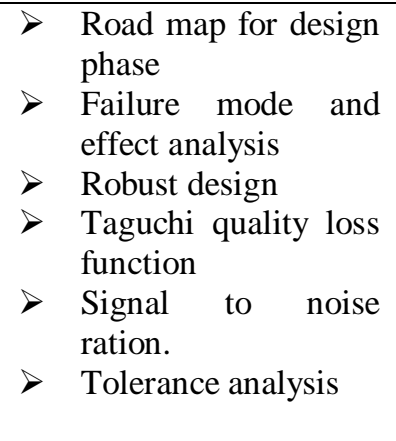 & $\begin{array}{ll}> & \text { Road map for verify } \\
& \text { phase } \\
> & \text { Reliability } \\
> & \text { Design evaluation } \\
> & \text { Design verification } \\
& \text { tools } \\
> & \text { Design review inputs } \\
> & \text { Transfer to production } \\
> & \text { Pilot production plan } \\
> & \text { Design Validation }\end{array}$ \\
\hline
\end{tabular}

Summary of Define Phase is as follows

$>\quad$ Identify the projects which are linked to big Y.

$>$ Select the team which is ready to contribute.

$>$ Prepare team charter and get it approved.

$>$ Train team members.

$>\quad$ Map the process

$>$ Carry out value analysis.

$>$ Walkthrough process.

$>\quad$ Analyze the past data from various view points.

$>$ Identify quick wins and implement.

$>$ Record results of quick wins.

\subsection{Measurement Phase}

In this phase data is gathered and analyzed that describes with precision and accuracy. What is happening? What is current or baseline, level of performance of the process that creates the problem? It also produces some preliminary ideas of possible causes for problem. Identify the measurement standards that are important to stakeholders. Convert customer needs into project objectives.

The goals of the measure phase are as follow

$>$ Identify customers and their needs

$>$ Derive specific requirements to the system

$>$ Determine the corresponding output measures and their target values and tolerances.

The significant improvement could be accomplished by:

$>$ Reduction of cycle time,

$>$ Reduction of control time,

$>$ Reduction of tool costs, and

$>$ Minimizing or eliminating scrap.

\subsection{Analyze Phase}

The analysis phase deals with identifying the critical factors embedded in the current operation that could be improved to minimize waste. Prior to starting this phase, the project champion reviewed the collected data to filter out any type of noise and disturbance. Data mining is then used to identify main types of wastes for each machine to perform the corrective actions. Develop design alternatives, identify the best combination of requirements to provide value within constraints, develop conceptual designs, evaluate, select the best components and develop the best available design. Analyse the alternatives available for meeting project aims. Identify the behaviour of comparable best-inclass designs. At this stage it is important not to miss out any possible cause. If an important $\mathrm{X}$ is missed out, it will never be analyzed for validation.

The tools used for listing Xs are:

$>$ Brainstorming

$>$ Process map

$>$ Cause effect diagram

$>\quad$ Why-Why analysis

Prioritize Xs - After the Xs have been listed using process map or cause effect diagram, these need to be prioritized. The tools used to prioritize Xs are as follow

$>$ Cause- Effect Matrix

$>$ Pareto analysis

$>$ Pugh Matrix

Validate Xs - There are three steps to validate Xs. They are as follow.

$>$ Scatter Plot

$>$ Tolerance stack up analysis

$>\quad$ Design failure made $\&$ effects analysis

\subsection{Design New Product}

This stage of DMADV includes both a detailed and high level design for the selected alternative. The elements of the design are prioritized and from there a high level design is developed. Once this step is complete, a more detailed model will be prototyped in order to identify where errors may occur and to make necessary modifications. Develop a high level design, Develop exact specifications, Develop detailed component designs, Develop related processes, Optimize design. Design the new product, service, or process. Utilize prognostic modelling, simulation, prototypes, pilot trials, and other techniques in order to confirm the design's ability to meet the established aims of the project. 


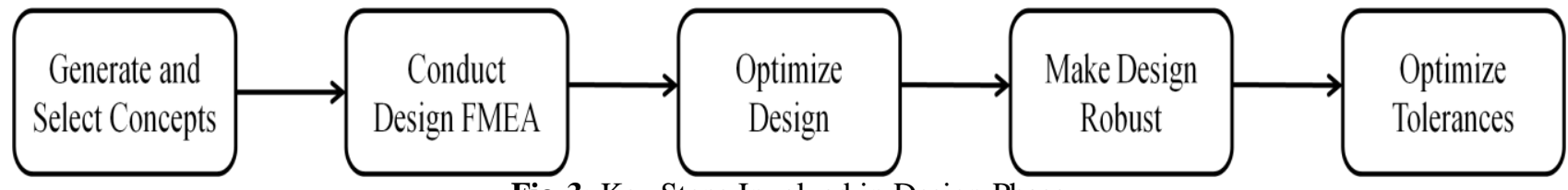

Fig-3: Key Steps Involved in Design Phase

\subsubsection{Signal to Noise Ratio}

The signals to noise ratio combines, in a single measure, information on both the average level and the spread of a variable. The goal is to always maximize $\mathrm{S} / \mathrm{N}$ ratio. The types of signal to noise ratios are

Lower is better ratio- applies to variables where lower value is preferable.

Higher is better ratio- applies to variables where a higher value is preferable.

Nominal is best ratio- applies to variables where deviations from a target value are undesirable

\subsubsection{Tolerance Analysis}

Tolerance analysis (TA) is the process of taking known tolerances and analyzing the combination of these tolerances at an assembly level.

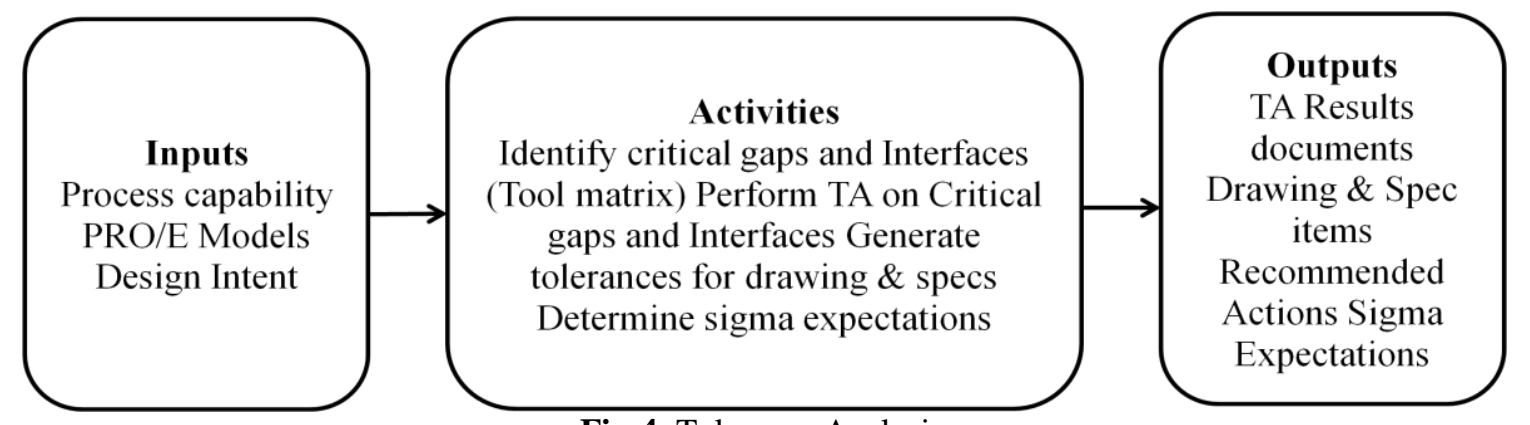

Fig-4: Tolerance Analysis

\subsection{Verify Product Design}

In the final phase, the team validates that the design is acceptable to all stakeholders. Will the design be effective in the real world? Several pilot and production runs will be necessary to ensure that the quality is the highest possible. Here, expectations will be confirmed, deployment will be expanded and all lessons learned will be documented. The Verify step also includes a plan to transition the product or service to a routine operation and to ensure that this change is sustainable. Verify the efficiency of the new product or process in a real world situation.

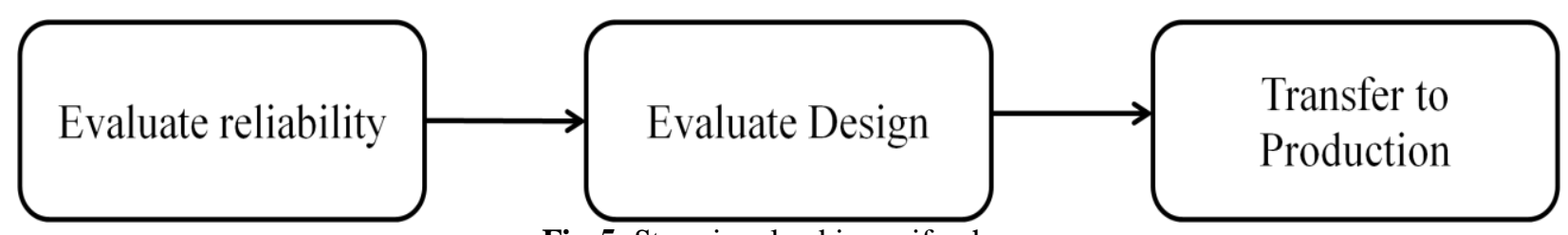

Fig-5: Steps involved in verify phase

\subsubsection{Design Verification}

It involves checking inputs/outputs at each stage as per Design Verification Plan. It includes-

$>$ Calculation Checks

$>$ Peer review

$>$ Proto test

$>\quad$ Lab trials

$>$ Simulations

D Benchmarking with existing designs available in the market

\subsubsection{Design Reviews}

Cross functional review to conform if design team has not missed out on any key items such as

$>$ Customer needs

$>\quad$ Manufacturability or assembly issues

$>$ Serviceability issues

$>$ Inspectability issues 


\subsubsection{Transfer to Production}

The implementation and the handover to the process owner occur after the successful piloting.

\subsubsection{Pilot Production Plan}

Steps involved in pilot production are as follow

- $\quad$ Prepare pilot production plan

- Carry out the pilot production.

- Analyze the results

- Carry out optimization.

Most important tools used are as follow

- PDCA cycle

- Project Management tools (Gantt chart, Network plan)

- Change management tools (Communication plan, stake holder analysis)

- Documentation

- SOP s

- $\quad$ KPI systems

- Control Charts

- $\quad$ Process flow diagrams.

\subsubsection{Design Validation}

The objectives of design validation are

$>$ To validate the design actually works in the real operating environment

$>$ May be part of initial design verification plan document or may be developed separately

$>$ If multiple applications are foreseen for new product, plan to cover all possible applications/environments in which the product is likely to be used.

\section{FUTURE SCOPE OF WORK}

Investigation as regards application of six sigma methodology to Indian automobile industry for reducing cost of quality is done for manufacturing processes. However as stated above, Six Sigma Methodology is industry independent and it is applicable to all business process. Viz. Purchasing, marketing, financial marketing, finance etc. Future work may be taken up as follows.

- Application of six sigma for non manufacturing processes in Indian automobile industry.

- Application of six sigma to Indian engineering industry viz. non automobile companies.

- Application of six sigma in hospitality industry, Application of six sigma in small scale industry.

\section{CONCLUSION}

In order for DMADV to be successful, the company will need to understand the customer's needs and decide which needs are being met and which needs should be improved upon. Complete evaluations of the existing processes need to be made in order to determine how you can satisfy your customers while saving money.Six sigma is methodology and a powerful quality improvement and design improvement tool. Organizations that have adopted Six Sigma indicate they have chosen it for several reasons. Organizations indicated that they generally adopted the Six Sigma technology in order to lower costs, increase time to market, and improve both process and product and service quality. In addition, they intended to institutionalize Six Sigma as a company culture or state of mind. Organizations implementing Six Sigma reveal product and service quality improvement, cost reduction, and significant savings due to Six Sigma projects focus on bottom line results. The success of Six Sigma projects is also due to its results orientation, data driven and ability to align the goals with objectives across the organizations. It is used by Indian automobile industry for supplier quality improvement. It helps in defect reduction, process improvement, inventory reduction, productivity improvement, reduction in customer complaints, reduction in field returns, reduction in field failures, reduction in warranty costs, and etc leading reduction in Cost of Poor Quality. Lean is supportive to Six sigma methodology \& during the process walk through value stream mapping is done to reduce waste (MUDA) from the system.

\section{ACKNOWLEDGMENTS}

First of all, I would like to show my thanks and gratitude to my project guide Prof. T. Z. Quazi for their time, effort and guidance for the accomplishment of this project. To the HOD, Prof. S. N. Teli, following my progress and correcting my path the monitoring guidance and the advisor who was always there. I also would like to express my thanks to the Principal Dr. Manjush Deshmukh, for their contribution in the paper work.

\section{REFERENCES}

[1] Garima Chaudhary, (2014), Six Sigma Concepts: a Complete Revolution, International Journal of Emerging Research in Management \&Technology, Volume-3, Issue-2, PP $82-86$.

[2] peter mutua mutia, stephen morangi nyambegera, (2014), six sigma approach for quality improvement and its future in kenyan organizations: a research agenda, International journal of science commerce and humanities, Volume no 2 no 1, 125- 136.

[3] Vipin s. Patil, Sunil r. Andhale, izhak d. Paul, (2013), A review of DFSS: methodology, implementation and future research, International journal of innovations in engineering and technology (ijiet), Vol. 2, 369 to 375 .

[4] Nurul fadly habidin, sha?ri mohd yusof, (2013), Critical success factors of lean Six sigma for the Malaysian Automotive industry, International journal of lean six sigma, Vol. 4 no. 1, 60- 82.

[5] Nurul Fadly Habidin, Sha'ri Mohd Yusof, Che Mohd Zulkifli Che Omar, Syed Ismail Syed Mohamad, Sharul Effendy Janudin, Baharudin Omar, (2012), Lean Six Sigma Initiative: Business Engineering Practices and Performance in Malaysian Automotive Industry, IOSR Journal of Engineering (IOSRJEN) 
ISSN: 2250-3021 Volume 2, Issue 7(July 2012), PP 13-18

[6] Nabeel Mandahawi, Rami H. Fouad, Suleiman Obeidat, (2012), An Application of Customized Lean Six Sigma to Enhance Productivity at a Paper Manufacturing Company, Volume 6, Number 1, Feb. 2012 ISSN 1995-6665 Pages $103-109$

[7] Lou Magritzer, PE, Jichao Xu, (2012), Six Sigma and the Cost of (Poor) Quality, Vol. 3 Iss: 2 pp. 159 - 182

[8] Subhash s. Tirumalai, (2012), Role of design for six sigma (dfss) in designing and Building test rigs for Commercial aircraft, Quest global services.

[9] Yang, Ching-chow, (2010),Six sigma and total quality management, Intech.

[10] Sameer Kumar, Kenneth F. Bauer, (2010), Exploring the Use of Lean Thinking and Six Sigma in Public Housing Authorities, University of St. Thomas

[11] B. Tjahjono, P. Ball, V.I. Vitanov, C. Scorzafave, J. Nogueira, J. Calleja, M. Minguet, L. Narasimha, A. Rivas, A. Srivastava, S. Srivastava, Yadav, (2010), Six Sigma: a literature review, Vol. 1 Iss: 3 pp. $216-$ 233

[12] Mohamed Gamal Aboelmaged, (2009), Six Sigma quality: a structured review and implications for future research.

[13] Raymond vella, sekhar chattopadhyay john p.t. Mo, (2009),Six sigma driven enterprise model transformation, International journal of engineering business management, Vol. 1, no. 1, 1-8.

[14] Jim franklin, (2009), A case study for DFSS, Six sigma experts.

[15] Rafat a. Samman, ian graham, (2007),The six sigma project management Strategy, Belfast, uk, association of researchers In construction management, 587-596.

[16] M. Soković, D. Pavletić, E. Krulčić, (2006), Six Sigma process improvements in automotive parts production, Journal of Achievements in Materials and Manufacturing Engineering, VOLUME 19, ISSUE 1, November 2006.

[17] Role of design for six sigma in total product development, (2006), Six sigma academy international, llc, new York.

[18] frank t. Anbari, young hoon kwak, (2004), success factors in managing six sigma projects, Project management institute research conference, london, uk, 1 to 14.

[19] Charles huber, glenn h. Mazur, (2003),QFD and design for six sigma, 14th symposium on QFD.

[20] Gregory H. Watson, (2003), The Elements of Design for Six Sigma, GOAL/QPC Press, 01 to 16.

\section{BIOGRAPHIES}

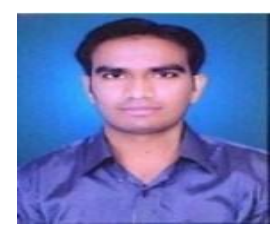

Devendra Gajanan Pendokhare currently pursuing Masters Degree Program in Manufacturing System from Saraswati college of engineering, Kharghar, New Mumbai, Maharashtra, India, also working as Lecturer in Government Polytechnic, Vikramgad in Mechanical Engineering Department. BE in Mechanical Engineering from Nagpur University.

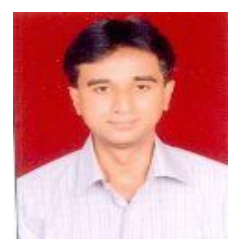

T. Z. Quazi currently working as Associate Professor and Head of Department at Saraswati College of Engineering, Kharghar, Navi Mumbai. He has over 16 years of experience in teaching field. He has published various research papers in national and international journals

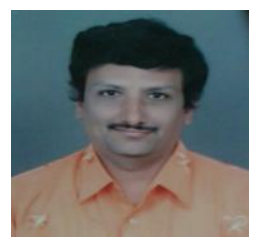

P. S. Kulkarni currently working as Lecturer at Government Polytechnic, Vikramgad. He has 20 years of experience in teaching field. Completed ME in Manufacturing Technology from thapar university Patiyala. 